CONTRIBUTIONS FROM THE ZOÖLOGICAL LABORATORY OF

THE MUSEUM OF COMPARATIVE ZOÖLOGY AT HAR-

VARD COLLEGE. E. L. MARK, DIRECTOR. No. I65.

\title{
POSTERIOR CONNECTIONS OF THE LATERAL VEIN OF THE SKATE.
}

HERBERT W. RAND AND JOHN L. ULRICH.

FOR several years the senior author has used the skate to illustrate to classes in the comparative anatomy of vertebrates the main features of the primitive circulatory system of vertebrates. The injection of the systemic veins of the skate is attended with more or less difficulty, especially at the hands of students of little experience, and even under the most favorable circumstances it is difficult, if not impossible, to secure a complete injection of the veins by the methods ordinarily prescribed (see, for example, T. J. Parker, '95, pp. 48-49). The difficulty lies partly in the fact that the veins are well provided with valves, which impede the flow of the injection mass in a direction the reverse of that of the blood-flow, and partly in the presence of large thin-walled sinuses which are likely to rupture before the injection mass can be forced into the smaller vessels and those more remote from the point of injection. Although a large number of injected skates had come under observation in the laboratory, the relations of certain of the veins in the region of the kidneys had never been clearly demonstrated.

The veins of certain foreign species of skate have been well described, notably by T. J. Parker ('8I). Conditions similar to those found in foreign skates are to be expected in our local species. Nevertheless, it seemed to the authors to be worth while to determine precisely the condition of the vessels whose connections were in doubt, especially in view of the fact that there was strong evidence of one striking difference between our common skate and the species described by Parker, in the pos- 
terior connections of the lateral veins. The importance of a complete knowledge of the details of skate anatomy is increased by the fact that the skate is, in some respects, so peculiarly adapted for use in the laboratory work of classes in comparative anatomy. In another paper (Rand, :05) attention has been called to the advantages of the skate for this purpose, where also methods of injecting the blood vessels are discussed.

The first complete description of the connections of the lateral vein of the skate is that given by T. J. Parker in his paper "On the Venous System of the Skate (Raja nasuta)" in I88I. Previous to Parker's description these veins had been imperfectly described by several anatomists. Monro (:85) observed the lateral veins in skates, but did not determine their posterior extent and connections. Robin ('45) gave an incomplete and not very clear account of the lateral veins of Raia clavata L., $R$. mbus L., and $R$. batis L., but at first regarded them as lymphatic vessels. He described the two lateral vessels as inosculating at their posterior ends. He afterwards recognized the true nature of the vessels.

Parker ('8I) gave a complete and clear account of the chief veins of Raic nasuta. Figure I is a diagram showing the connections of the important vessels as represented in the figure accompanying Parker's paper. A similar figure is given in his Zootomy ('95, p. 53). According to Parker's account, the lateral vein (vn. l.), having received the several brachial veins, opens anteriorly into the precaval sinus. Throughout its extent along the lateral wall of the abdominal cavity, the lateral vessel receives veins from the abdominal walls. The nomenclature used above is not that of the paper cited, but corresponds to that of Parker's later paper ('86) on the blood vessels of Mustelus antarcticus. Posteriorly it receives the femoral vein and just back of that point becomes continuous with a large trunk which " passes dorsalwards, ... . curving along the posterior wall of the pelvic cavity, then passing on to the lateral wall of the cloaca, along which it takes its course as far as to the rectal gland, where, with its fellow of the opposite side, it enters a hinder prolongation of the cardinal sinus, first receiving numerous small veins from the cloaca and rectum" (Parker, '8I, pp. 4I5-4I6). 
"These latter, I have no doubt," says Parker, "although I have not actually proved it, anastomose with factors of the portal vein" (p. 4I6). The large trunk which constitutes a direct continuation of the lateral vein from its femoral region into the cardinal sinus was called by Parker the ilio-hamorrhoidal vein because it "seems to correspond in all essential respects to the iliac vein" and "also receives the hæmorrhoidal veins from the rectum and cloaca" (p. 416). The arrangement described by Parker is virtually that of a continuous large venous trunk open-

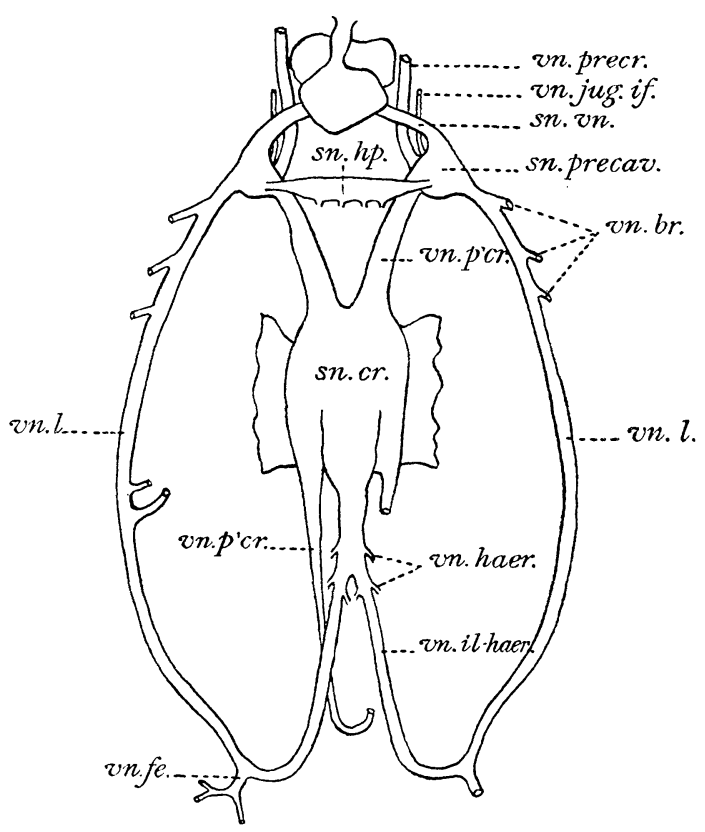

FIG. r.-Venous system of Raia nasuta. After T. J. Parker. sn. cr, cardinal sinus; sn. hpp., hepatic sinus; sn.precaz., precaval sinus; $s n$. z'n., venous sinus; $v^{\prime} n$. br., brachial veins; vn. fe., femoral vein; vn. her., hæmorhoidal veins; an. il-har., ilio-hæmorrhoidal veins; $z n . j u g$. if., inferior jugular vein; $\tau^{\prime \prime}$. l., lateral vein ; $z^{\prime} n$. ficr., postcardinal vein ; vn.precr., precardinal vein.

ing at its anterior end into the precaval sinus and at its posterior end into a posterior extension of the cardinal sinus, its chief tributaries being the brachial and femoral veins and veins from the abdominal wall.

Jourdain ('59) in his "Recherches sur la Veine Porte Rénale," does not mention the lateral veins, but describes the femoral 
veins in Raia clavata $\mathrm{L}$. as opening each into the corresponding renal portal vein.

Hochstetter ('88) gives the following account of the lateral veins of Spinax [= Squalus] acanthias: "Neben den Venæ subclaviæ münden caudalwärts von ihnen jederseits eine Vene, in die Cardinalvenen, die Seitenvene..... Diese beiden Gefässe wurzeln in einem Venennetze, welches die Kloake umspinnt und mit den Pfortaderzweigen des Enddarmes anastomosirt. Aus diesem Netze gehen rechts und links die beiden Venen hervor, welche angeschlossen an die dorsale Fläche des Beckenknorpels zunächst die Vene der hinteren Extremität aufnehmen und hierauf umbiegend, geradeaus kopfwärts verlaufen und auf diesem Wege die Venen der Bauchmuskeln aufnehmen " (p. I26). In the rays, Hochstetter says, the lateral veins exhibit substantially the same condition as that described for Squalus.

We were led to investigate the posterior connections of the lateral vein of the skate owing to the fact that, in the numerous animals which had come under observation in the laboratory, there had never been seen the least evidence of the "iliohæmorrhoidal " trunks described by Parker for Raic nasuta. In a freshly-killed skate ( $R$. erinacea or $R$. levis, Fig. 4) the lateral veins, lying just beneath the peritoneum, are conspicuous vessels because of the blood contained in them. They may be followed back to the pelvic region, where they disappear from view. The cardinal sinus is usually well filled with blood and a posterior extension of this sinus may be traced back to the base of the rectal gland. This extension evidently corresponds to the "hinder prolongation of the cardinal sinus" described by Parker as receiving the ilio-hæmorrhoidal veins, but no large trunks are to be seen opening into it. Attempts to trace the uninjected vessels by dissection resulted negatively, so far as any connection between the hind end of the lateral vein and the cardinal sinus is concerned, although a connection of the lateral vein with a vein from the pelvic fin was found. Furthermore, observation of a large number of injected skates had given no evidence of the existence of "ilio-hæmorrhoidal " veins. These injections, however, being of raw starch or of plaster of Paris, were not calculated to show a connection between lateral vein 
and cardinal sinus by means of minute vessels, if such existed. Accordingly we undertook to determine if any connection whatever was to be demonstrated.

Six fresh skates were secured, four of them being the common Raia erinacea and two R. levis. Our operations and results upon these six animals are described below. In each case the caudal vein was injected for the purpose of differentiating the renal portal connections. The celloidin injections were made with very thin, easily flowing celloidin colored with finely pulverized carmine or Prussian blue. Careful dissections and drawings of the injected vessels were made by Mr. Ulrich.

\section{Raia lavis: young male.}

I. Renal portal system injected, wia the caudal vein, with blue celloidin.

Minure separated masses of the celloidin appeared in the postcardinal veins, apparently having passed through the renal capillaries. A considerable quantity of celloidin from this source collected in the cardinal sinus and some of it made its way back into the posterior or rectal prolongation of that sinus.

2. Left lateral vein injected posteriorly with red celloidin.

The red mass appeared on the walls of the cloaca and rectum in a close network of very fine vessels extending forward to, and a little beyond, the base of the rectal gland. Small vessels connected with this network conveyed the celloidin along the ventral margin of the mesorectum, in the region of its attachment to the rectum, apparently into the posterior end of the rectal prolongation of the cardinal sinus. Here an interval of only three or four millimeters separated the blue and red injection masses.

The dissection of this fish proved that both the red and the blue celloidin had entered the rectal prolongation of the cardinal sinus. The failure of the two masses actually to meet was doubtless caused by the inclusion between them of a quantity of gas for which there was no avenue of escape. The lateral vein received 'two trunks from the pelvic fin. The larger one of the two emerged from the fin dorsal to the end of the girdle and 
just posterior to the iliac process. The smaller vein left the fin on the anterior side of the first or pre-axial fin-ray.

\section{Raia erinacea: young male.}

I. Renal portal system injected, via the caudal vein, with blue celloidin.

A small amount of the celloidin appeared in the cardinal sinus.

2. Left lateral vein injected posteriorly with red celloidin.

The mass did not appear on the rectum.

During the progress of the injection the posterior margin of the left pelvic fin was cut away. The red celloidin escaped from a small vessel lying along the median edge of the clasper.

In the dissection of this fish the lateral vein was traced to the wall of the cloaca, where it was lost in fine branches. A large vein from the pelvic fin was found opening into the lateral vein at a point dorsal to the girdle and just posterior to its iliac process.

\section{Raia erinacea: female.}

I. Renal portal system injected, via the caudal vein, with blue (raw) starch.

The starch mass did not pass into the cardinal sinus.

2. Left lateral vein injected posteriorly with red celloidin.

A fine anastomosing network on the cloaca and rectum was injected, as in I.

The left pelvic fin was cut, as in II. There was slight evidence of the red celloidin at the cut surface.

By dissection, the lateral vein was traced back along the pelvic region of the abdominal wall and onto the lateral wall of the cloaca along which it ran, giving off numerous branches and rapidly diminishing in caliber, to a point about 15 millimeters posterior to the rectal gland, where it became completely lost in a fine network.

The lateral vein was found to receive from the pelvic fin a fairly large trunk which emerged from the fin on the anterior side of the first or pre-axial fin-ray. 


\section{Raia erinacea: large male.}

I. Blue starch injected into the caudal vein.

The blue starch appeared in the left lateral vein and filled the greater portion of it, together with some of its branches from the body wall.

Dissection of the animal showed that the renal portal system was fully injected. The position and connections of the vein which put into direct communication the renal portal and lateral systems are represented in Figure 2. Lying transversely on the left dorsal body wall was found a large vein (Fig. 2, x) opening at

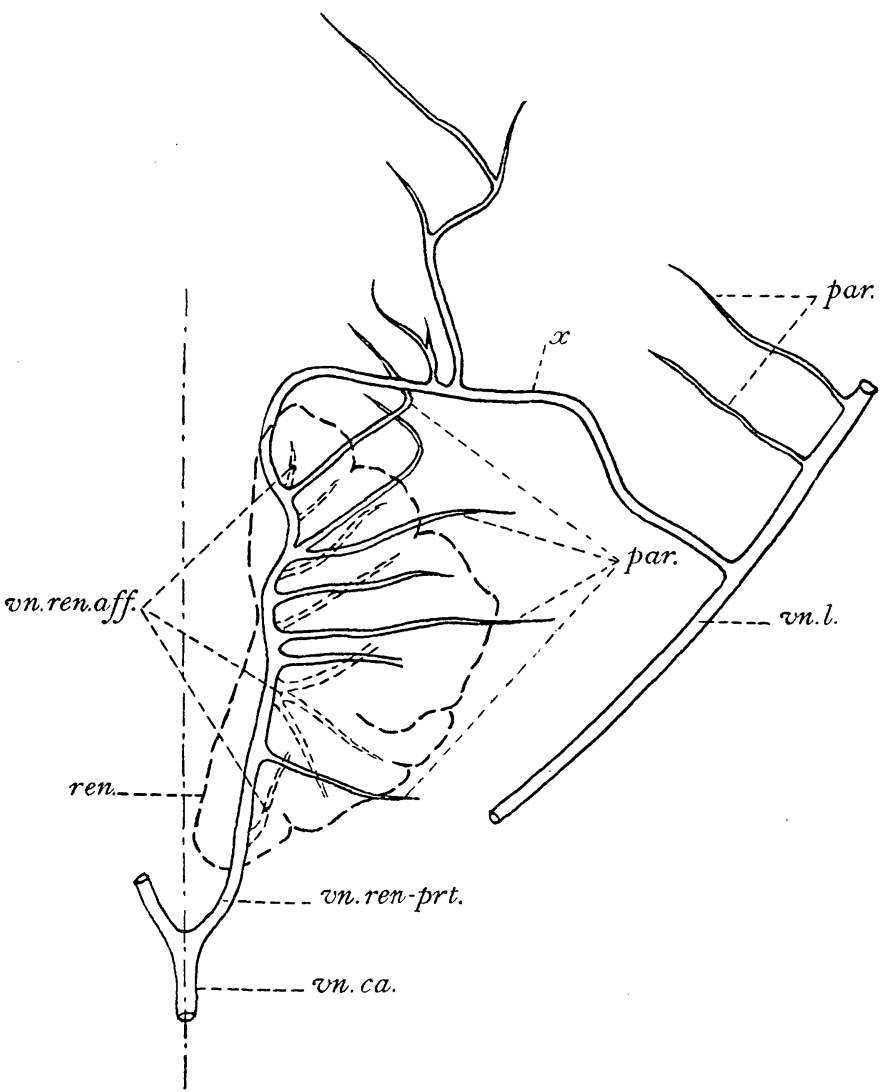

FIG. 2.- Showing the connection found in Case IV between the renal portal system and the lateral vein. par., parietal branches of the renal portal and lateral veins; ren., kidney; wn. ca., caudal vein; $v^{\prime} n$. l., lateral vein; $v n$. ren. aff., afferent renal veins; $a^{\prime} n$. ren-prt., renal portal vein ; $x$, vein connecting renal portal and lateral veins. 
its one end into the left lateral vein, and at its other into a large anterior renal portal component, which was virtually a direct continuation of the renal portal vein itself forward on the dorsal body wall. Jourdain ('59) describes a similar anterior component of the renal portal system.

The extreme posterior end of the lateral vein was found to be not injected.

\section{Raia lavis: very large female.}

I. Renal portal system injected, via the caudal vein, with blue starch.

2. Left lateral vein injected posteriorly with red celloidin.

A particularly full injection of the branches of the posterior part of the lateral vein was secured. The mass appeared on the walls of the cloaca and rectum in an anastomosing network of fine vessels, which were traceable along the rectum to a region about one centimeter anterior to the duct of the rectal gland. The mass was seen also in small vessels on the ventral margin of the mesorectum, and a considerable quantity of it passed through the rectal extension of the cardinal sinus into the main part of that sinus.

The left pelvic fin was cut, as in preceding cases, and the red mass escaped from small vessels along its median edge.

The dissection of this animal demonstrated clearly a connection between the venous network on the rectum and the cardinal sinus. The lateral vein was traced forward a short distance on the side of the rectum and there broke up into fine branches which anastomosed with vessels of the network. Along the margin of the mesorectum, in the region of the base of the rectal gland, several small vessels resolved themselves out of the network and communicated with the posterior end of the rectal extension of the cardinal sinus.

From the pelvic fin the lateral vein received two large trunks and one very small vein (see Fig. 4). The largest trunk emerged from the fin just posterior to the iliac process of the girdle, corresponding, therefore, with the one vein found in II and with the posterior one of the two veins found in I. This 
trunk, from its position and size, is doubtless entitled to the name, femoral wein. It receives one large branch from the median side of the basipterygium. The remainder of its branches are distributed upon the external side of the basipterygium, collecting the blood from much the greater portion of the fin. A second and considerably smaller vein emerged from the fin on the anterior side of the pre-axial fin-ray, corresponding with the vein found in III and with the anterior one of the two veins found in I. The branches of this vein were distributed around the large pre-axial fin-ray, the main axis of the vein lying along the anterior side of the ray.

The third one of the three veins mentioned as entering the lateral vein from the pelvic fin was a very small vessel which lay just anterior to the iliac process of the girdle.

\section{Raia crinacea: small femalc.}

I. Renal portal system injected, vic the caudal vein, with blue celloidin.

A trace of the celloidin appeared in the right postcardinal vein.

2. Right lateral vein injected posteriorly with red celloidin.

The mass entered a fine network of vessels on the cloaca and rectum, passed through minute vessels lying along the ventral margin of the mesorectum, and a small quantity of it collected in the rectal extension of the cardinal sinus.

By dissection, the lateral vein was traced up to the wall of the cloaca (see Fig. 3), where, at a point nearly in the same transverse plane with the anterior end of the external cloacal aperture, it divided into two branches. Each of these immediately broke up into fine branches which anastomosed with vessels of the network. On the dorsal wall of the rectum and just behind the rectal gland, the network resolved itself into a system of fine vessels (Fig. 3, A and B, $\boldsymbol{c}^{\prime \prime}$.) lying nearly parallel with one another, frequently anastomosing, and converging forward into fewer and larger vessels in such a way that there was a gradual transition from the rectal network into the single very narrow lumen of the posterior tip of the cardinal sinus.

No veins from the pelvic fin were injected. 
Examination of a number of skates which had been injected (by students) with starch or a starch-gelatin mixture (see Rand, :05) brought to light several animals in which the rectal venous network had been more or less completely filled from the cardinal sinus. In these cases, the lateral vein had been injected forward, but not backward. The cardinal sinus had

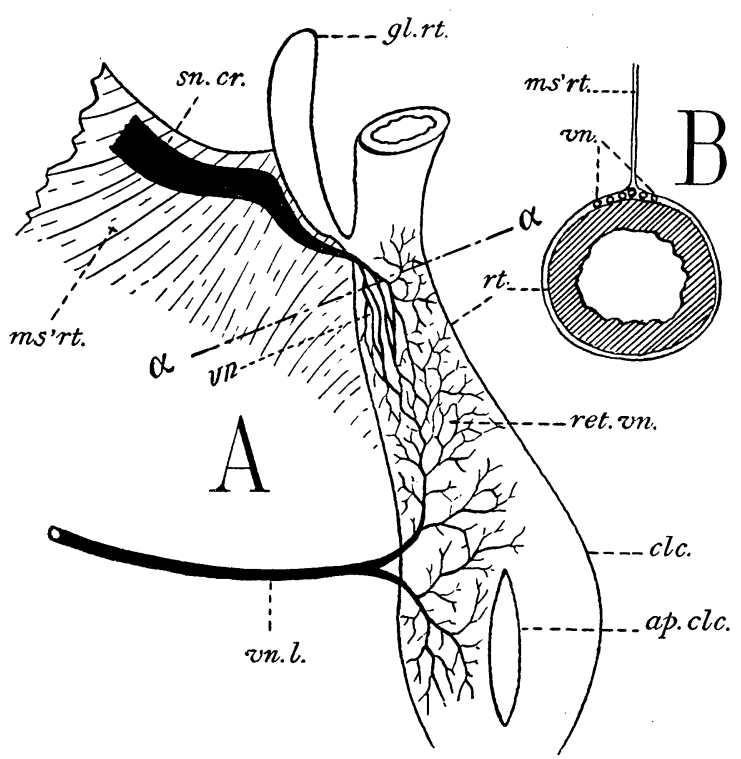

FIG. 3.-Showing the relation found in Case VI between the posterior end of the lateral vein and the cardinal sinus.

A. The cloacal region is seen from the ventral aspect, but the rectum is twisted through $90^{\circ}$ so as to bring into view the right side of its anterior region as well as the right side of the rectal gland and mesorectum.

B. Cross section (enlarged) of the rectum at $\boldsymbol{\alpha}-\boldsymbol{a}$.

$a p$. clc., cloacal aperture ; clc., cloaca ; gl.rt., rectal gland; ms.rt., mesorectum; ret. vn., venous network on cloaca and rectum; rt., rectum; sn. cr., rectal prolongation of cardinal sinus: vn., veins connecting rectal venous network with cardinal sinus; vn. l., lateral vein.

filled from the precaval (Cuvierian) sinus and the mass had made its way back through the rectal extension of the cardinal sinus into the rectal network. This network, therefore, may be injected either from behind, by way of the lateral vein, or from before, by way of the cardinal sinus. Figure 4 shows the lateral vein in its entire extent with its connections as found in 


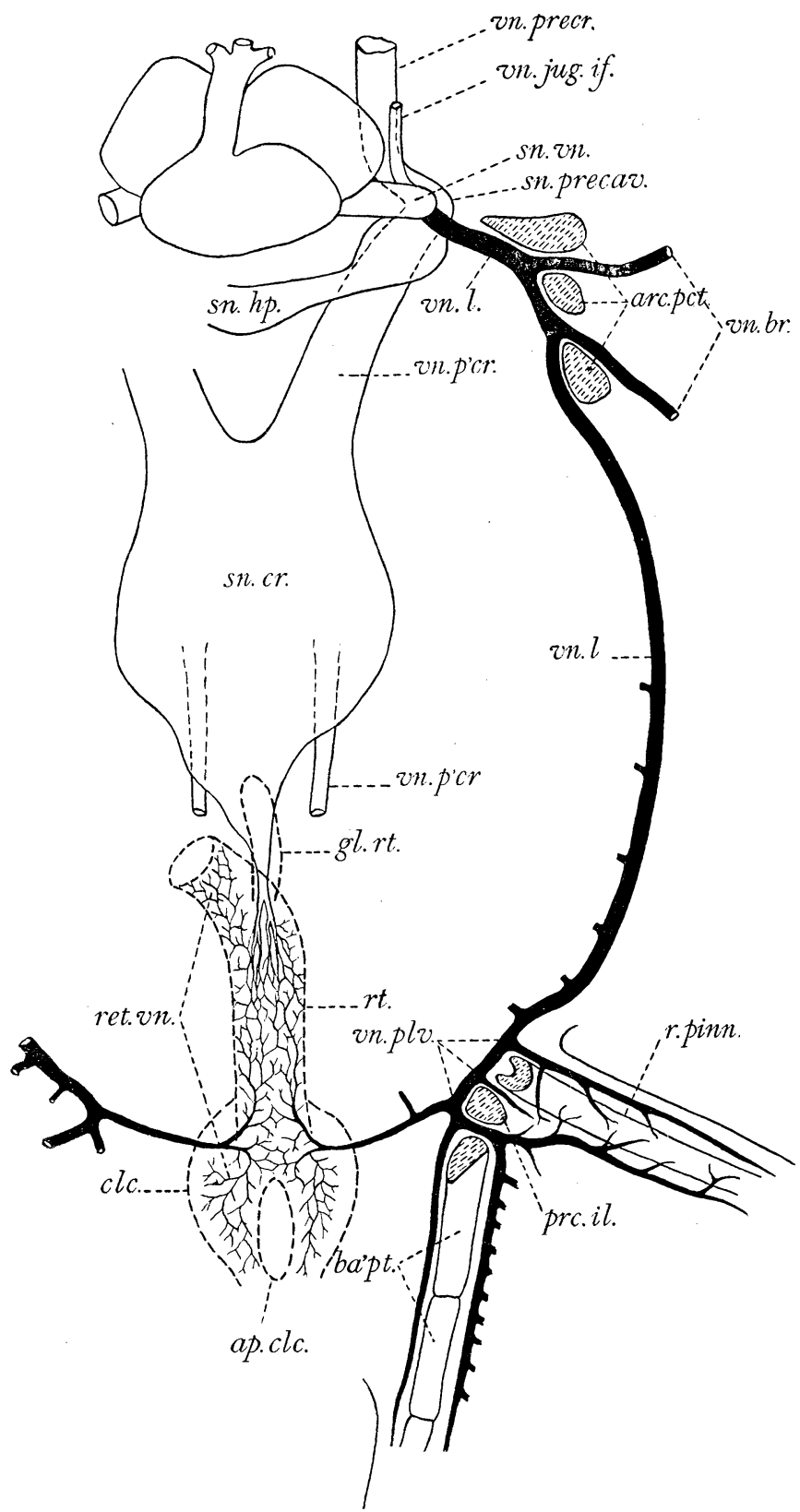

FI( $;$. 4. The lateral vein and its connections in Raia erinacea and $R$. leevis. Ventral view. $a r c . p c t$., pectoral girdle ; $a p$. clc., cloacal aperture: $b a^{\prime} p t$., basipterygium ; clc., cloaca ; gl. rt., rectal gland; prc. il., iliac process of pelvic girdle; r.pinn., pre-axial ray of pelvic fin ; ret. $v n$., venous network on cloaca and rectum; rt., rectum; sn.cr., cardinal sinus; sn. hp., hepatic sinus; sn. precav., precaval sinus; $s n . v n$. , venous sinus; $v n$. br., brachial veins; vn. jug. if., inferior jugular vein; vn. l., lateral vein; vn.p'cr., postcardinal vein; vn. plv., veins from pelvic fin; vn.precr., precardinal vein.

This content downloaded from 184.102.209.212 on February 18, 2018 20:19:18 PM All use subject to University of Chicago Press Terms and Conditions (http://www.journals.uchicago.edu/t-an 
Do the veins of the rectal network communicate directly with the posterior factors of the hepatic portal system, as stated by Hochstetter for Squalus, and as thought probable by Parker ('8 I) for Raia nasuta?

Good starch injections of the intestinal veins often result in the demonstration of a venous network on the rectum in the region of the base of the rectal gland. The network which has been demonstrated by injection from the lateral vein often extends into the same region. It is improbable that there should be two distinct and non-communicating sets of veins in this same region of the intestine. In one case (I) the red celloidin passed through the venous network on the rectum and appeared in a very small vessel which was identified, with a fair degree of certainty, as the extreme posterior end of the mesenteric or dorsal intestinal vein, the hindmost trunk of the hepatic portal system. The failure of the celloidin to flow freely through the network into the hepatic portal vessels, granting that the connection exists, might well be due to the solidifying of the celloidin in the fine vessels of the network as the result of contact with moisture. The senior author has seen injected skates in which a yellow starch mass, injected backward into the mesenteric vein, appeared actually to meet, in the region of the rectal gland, a blue starch mass which had made its way into the rectal network via the rectal extension of the cardinal sinus, the two masses clearly lying in the same vessels.

With a view to getting more conclusive evidence as to the relation between the rectal network and the hepatic portal system, the senior author secured some fresh skates of the common species, R. erinacea (at Woods Hole, Massachusetts, through courtesy of officials of the United States Bureau of Fisheries and of the Marine Biological Laboratory), and made injections in the following way. A fluid consisting for the most part of water, but containing a small amount of glycerin and colored with finely pulverized insoluble Prussian blue, was injected backward into one of the lateral veins. The rectal network immediately became very fully injected and the blue fluid passed along the mesorectum into the cardinal sinus, in the manner already described. Then a ligature, which had previously been 
passed around the narrow posterior end of the rectal extension of the cardinal sinus, was tightened so that further flow of the fluid into the cardinal sinus was prevented. A very light pressure on the syringe was maintained, with the result that the blue fluid appeared in the posterior region of the mesenteric vein and in its posterior branches, whence it passed forward, filling most of the veins on the intestine. The intestinal arteries were then injected, wia the anterior mesenteric artery, with a fluid similar to that used for the veins, but colored with pulverized carmine. There was no interference or mingling of the blue and red fluids on the intestine, nor was there any evidence that the blue fluid had passed through capillaries into arteries.

The injection of the Prussian blue fluid backward into the mesenteric vein gave similar proof of the continuity of the portal veins and the rectal network. The fluid appeared in extremely fine vessels over the entire intestinal wall and, passing through the rectal network, entered the cardinal sinus and both lateral veins.

To summarize, in Raia erinaced and $R$. levis (see the diagram, Fig: 5) :-

(I) There are no veins similar to the large ilio-hæemorrhoidal veins described by Parker for $R$. nasuta.

(2) The two lateral veins have a common origin in a close network of fine vessels distributed over the walls of the rectum and cloaca.

(3) This venous network communicates with the cardinal sinus by means of small vessels lying along the ventral margin of the mesorectum, in the region of its attachment to the rectal gland.

(4) The vessels of the rectal network communicate with the posterior factors of the hepatic portal system as stated by Hochstetter and as thought probable by Parker.

(5) The lateral vein receives the blood from the pelvic fin, there being, in addition to the chief femoral vein, one or two smaller vessels from the fin which open into the lateral vein independently.

The relations of the lateral veins to other parts of the venous system are, therefore, substantially as described by Hochstetter 
for selachians in general, except for the connection with the cardinal sinus via the cloaco-rectal network.

It is probable that the flow of blood throughout the entire length of the lateral vein is from the cloaco-rectal network and toward the precaval sinus. The steady increase in the diameter of the vein as it leaves the network and curves along the pelvic region points toward this view, as does also the presence, in the pelvic region of the vein, of valves placed so as to impede a posterior flow. The cloaco-rectal network is doubtless an indifferent region as regards flow, the blood passing from it into either the hepatic portal system, the cardinal system, or the

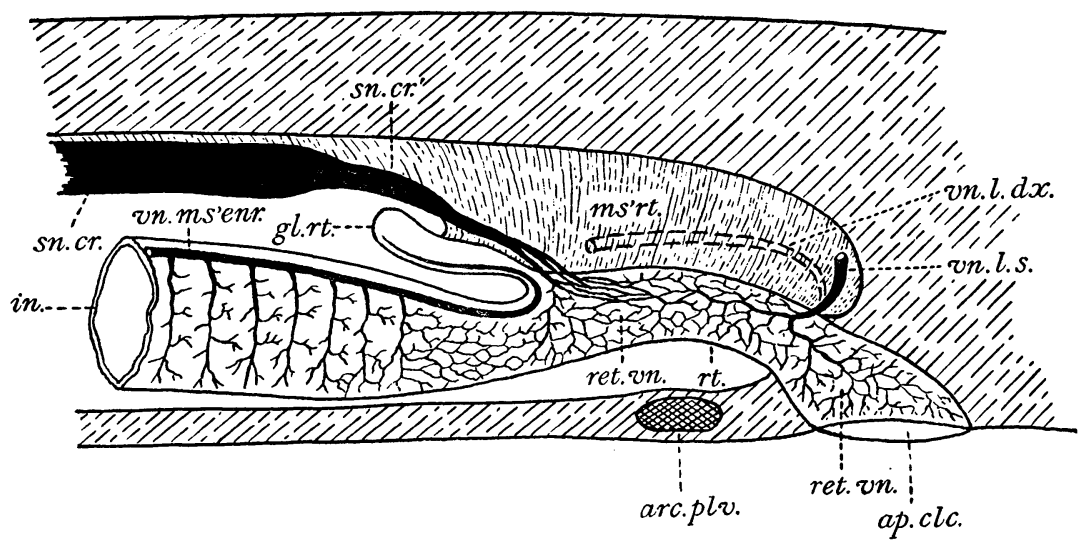

FIG. 5-Diagrammatic side view of cloaco-rectal region, showing relations of lateral veins, cardinal sinus, and mesenteric vein. ap. clc., cloacal aperture; arc. plv., pelvic girdle; gl. rt., rectal gland; in., intestine; ms'rt., mesorectum ; ret. vn., venous network on cloaca and rectum; rt., rectum; sn. cr., cardinal sinus; $s n . c r^{\prime}$., rectal prolongation of cardinal sinus; $v n$. $l$. $d x$, right lateral vein; vn. l. s., left lateral vein; vn. ms'enr., mesenteric vein.

lateral veins. The blood from both the pectoral and the pelvic fin of one side, therefore, passes to the heart by the same vein.

In two of the dissections made by Mr. Ulrich a suggestive condition was found. The lateral vein, steadily diminishing in caliber, was traced to the wall of the rectum where, at first glance, one would say that it became lost in the network. But close inspection revealed an extremely fine vessel which was virtually the continuation of the lateral vein along the side of the rectum. This fine vessel maintained a fairly straight course through the midst of the rectal network, of which, by reason of 
frequent anastomoses, it was really a part, and could be traced forward to the cardinal sinus, except for one or two interruptions where it completely lost itself by branching into the network. If the relatively short gaps in the continuity of this fine vessel were filled in and if the continuous vein thus formed should become nearly as large as the largest part of the lateral vein, the result would be the ilio-hæmorrhoidal vein described by Parker. The condition just described suggests the presence of either an incipient or a rudimentary "ilio-hæmorrhoidal" connection between lateral vein and cardinal sinus. An examination of embryonic stages might yield further information.

The direct connection existing in one case (IV, p. 355) between the renal portal system and the lateral vein is due apparently to the anastomosis of a parietal factor of the renal portal system and one of the parietal branches of the lateral vein. Normally these two sets of veins on the dorsal wall of the abdominal cavity come into close relation at their initial ends. This unusual relation of the lateral vein to the renal portal system is of no great importance in itself, but it is suggestive in connection with the theory that the lateral veins of elasmobranchs are represented in higher vertebrates by the abdominal vein. Just as the two lateral veins in the elasmobranch collect the blood from the walls of the cloaca and from the pelvic fins, so, in the urodele amphibian, the abdominal vein receives the veins from the urinary bladder (which is a derivative of the cloaca), and the two posterior components of the abdominal vein receive the veins from the hind legs. The chief difference is that, in the elasmobranch, the lateral system has no direct connection with the renal portal system, while in the amphibian each of the two posterior components of the abdominal vein is directly connected with the corresponding afferent renal portal vein. Development, as is well known, affords some evidence in favor of the homology. In consequence of the slight abnormality described above, there occurs in the veins on one side of the body in the kidney region of a skate an arrangement similar in all essential respects to that in amphibians. Such an anastomosis of a lateral and a renal portal component occurring on both sides of an elasmobranch and in the posterior region of the 
kidneys would yield a condition precisely like that seen in the relations of the abdominal, iliac, and renal portal veins of a urodele. This abnormal skate serves at least to suggest a possible way in which one of the differences in the arrangement of the veins of elasmobranch and amphibian may have arisen.

\section{BIBLIOGRAPHY.}

Hochstetter, F.

'88. Beiträge zur vergleichenden Anatomie und Entwicklungsgeschichte des Venensystems der Amphibien und Fische. Morph.Jahrb., Bd. I 3 , Taf. $2-4,7$ Textfig.

JOURDAIN, S.

'59. Recherches sur la veine porte rénale. Ann. Sci. Nat., 4me Série, Zoöl., Tom. I 2, pp. I 34-I 88,32 I-369, 5 pls. Monro, A.

(85. The Structure and Physiology of Fishes. Edinburgh, I785, I28 pp., 44 pls.

PARKER, T. J.

'81. On the Venous System of the Skate (Raja nasuta). Trans. and Proc. New Zealand Inst., vol. I3, pp. 4I 3-4I8, I pl.

PARKER, T. J.

'86. On the Blood-Vessels of Mustelus antarcticus. Phil. Trans. Roy. Soc. London, vol. I77, part 2, pp. 685-732, pls. 34-37.

PARKER, T. J.

'95. A Course of Instruction in Zootomy (Vertebrata). Macmillan, London and New York, xxiii +397 pp., 72 figs.

RAND, H. W.

:05. The Skate as a Subject for Classes in Comparative Anatomy; Injection Methods. Amer. Naturalist, vol. 39, pp. 365-379, fig. I. Robin, C.

'45. Vaisseaux lymphatiques chez les poissons. Rerue Zool. par la Societé Cuvierienne, Paris, Tom. 8, pp. 224-233, 46r. 